\title{
UMA ANÁLISE JURIDICA SOBRE O MARCO CIVIL DA INTERNET
}

\author{
Adriana Baker Goveia Araujo, Ana Augusta R. WestinEbaid
}

Universidade do Oeste Paulista - UNOESTE, Curso de Direito, Presidente Prudente, SP. E-mail: adrianabgaraujo@gmail.com

\section{RESUMO}

O objetivo geral da pesquisa é realizar um estudo sobre o Marco Civil da Internet (Lei no 12.965/14) por meio de uma análise jurídica, esclarecendo os seus principais pontos positivos e negativos, bem como um breve apanhado histórico da internet e o significado de alguns termos essenciais para o entendimento da referida Lei. Serão abordadas algumas hipóteses recentes de controle da rede (internet) no Brasil, bem como uma reflexão sobre a importância e correlação da internet com a globalização. Ao final ficará esclarecido que Leis mal explanadas pelos legisladores criam hipóteses de interpretações equivocadas, prejudicando desta forma o âmbito jurídico do direito digital, uma área pouco explorada e elucidada atualmente, necessitando de Leis específicas na área, como o Marco Civil da Internet (Lei no 12.965/14), Lei de Azeredo (Lei no 12.735/12) e Lei Carolina Dieckmann (Lei no 12.737/12).

Palavras-chave: Marco Civil; Rede; Internet; Lei; Brasil.

\section{A LEGAL ANALYSIS OF INTERNET CIVIL MARCO}

\begin{abstract}
The main objective of this research is to conduct a study of the Civil Internet Marco (Law No. $12,965 / 14$ ) by a legal analysis, explaning its main strengths and weaknesses, as well as a brief historical overview of the Internet and the meaning of some essential terms for the understanding the law. It will covered some recent cases of network control in Brazil, as well as a reflection of the importance and correlation of the internet with globalization. As a conclusion it will be clear that badly esplanades laws by legislators create chances of misinterpretation, damaging the way of legal framework of digital rights, in an area less explored and currently elucidated, requiring specific laws in the area, such as the Civil Internet Marco (Law No. 12,965 / 14), Azeredo Law (Law No. 12,735/12) and Carolina Dieckmann Law (Law No. 12,737/12).
\end{abstract}

Keywords: Civil Marco; Network; Internet; Law; Brasil. 


\section{INTRODUÇÃO}

No Brasil, os processos já são digitais, podendo ser acessados por qualquer computador que esteja conectado com a rede (internet). O que torna evidente, que a lei deve acompanhar essa evolução, por meio de normas que regulem esta nova realidade, não devendo ser versada por analogias ou outros mecanismos de nosso ordenamento jurídico, como o Código Civil, entre outros, em decorrência de sua importância e amplitude.

Entretanto, as leis não devem interferir ao ponto de impedir o funcionamento da rede, como por exemplo, controlar informações, extinguir a privacidade de seus usuários ou até mesmo ser utilizada de uma forma déspota pelo governo para controlar uma nação, uma vez que leis mal explanadas criam ambientes para interpretações duvidosas.

A internet deve ser livre e acessível como são nossas linhas telefônicas, onde somente são violadas judicialmente e em casos extremamente necessários. É um serviço liquido que não pode ser transgredido por qualquer motivo, pois o histórico da vida dos indivíduos encontra-se na rede (internet). Portanto, o objetivo deste estudo foi abarcar que a internet deve ser regrada por uma lei própria, para a proteção dos usuários e prestadores do serviço, uma vez que as normas são necessárias em qualquer setor de nossa sociedade.

\section{METODOLOGIA}

É um estudo voltado para duas áreas que se interligam atualmente, em decorrência da evolução tecnológica e da globalização - o direito e a informática. Consiste em uma análise de leis, bibliografias, doutrinas e artigos científicos, numa junção de dois assuntos pouco observados. Versando sobre uma temática importante para a evolução do pensamento jurídico, ampliando as possiblidades de interpretações e análises nas ciências jurídicas.

\section{RESULTADOS}

A internet passou por uma longa evolução até se tornar essa incrível ferramenta que conhecemos e utilizamos atualmente. É reconhecida como uma excelente biblioteca virtual, uma ferramenta de compra, divulgação do trabalho dos indivíduos, uma importante fonte de informação, sendo infinitas as possibilidades de suas aplicações. Devido a sua abrangência e amplo emprego, se faz necessário que ela seja regrada por Leis, passando a existir em nosso ordenamento jurídico, fazendo parte de nossa sociedade. No Brasil, essa Lei se denominou Marco Civil da Internet, sendo imprescindível uma interpretação e aplicação correta de seus artigos pelo poder judiciário.

\section{DISCUSSÃO}

A internet surgiu por meio da Agência de Investigação de Projetos Avançados dos Estados Unidos, sendo denominada incialmente de ARPANET (Advanced Research Projects Agency Network). Funcionava por meio de uma rede operacional de computadores à base de comutação de pacotes (as mensagens ou informações eram trocadas em "fatias" dentro de "pacotes"), possuindo a finalidade de comunicação militar em qualquer condição hostil, até mesmo no caso de um ataque nuclear. Posteriormente, foi responsável por compartilhar informações entre Universidades, obtendo um impulso comercial através do CompuServe, o primeiro provedor de serviços comerciais on-line. Em seguida, o pesquisador inglês Tim Berners-Lee criou a "World Wide Web", onde um computador poderia ser integrado com outros em uma rede mundial, interligando desta forma todas as informações. A principal ideia de finalidade da internet para Tim era que ela deveria manter-se aberta, ou seja, sem proprietários. (ABREU, 2009)

Com o passar dos anos a "rede" ampliou-se de tal forma, que atualmente está disponível para o uso comum da sociedade, como a maioria dos recursos tecnológicos já inventados, onde todos a utilizam para as mais variadas finalidades, como por exemplo, para o comércio, interação 
social, pesquisas, informações e diversas outras aplicações. Mantendo a todos conectados, ou seja, "globalizados".

A globalização denota uma integração econômica, social, cultural e política que envolve a todos. Onde a internet promove e contribui diariamente para a existência desta "conexão", representando para a nossa sociedade uma evolução incomensurável. Tornando-se indispensável à existência de uma lei capaz de regular os atos que são cometidos na rede, pois as normas devem evoluir com a coletividade e acompanhar a modificação dos seus costumes, gerindo desta forma a vida dos indivíduos.

No caso do Brasil, enfrentamos dificuldades para lidar com os cibercrimes, das mais variadas formas em que ele possa ocorrer, seja pedofilia na rede ou até mesmo um provedor que divulgou dados de seus clientes para empresas externas. Tudo se resume a uma insegurança jurídica brasileira, que possui a necessidade de adaptar suas normas para este novo cenário ao qual nos deparamos diariamente - a internet - que através de sua evolução, fez surgir novos termos, que são importantes para o entendimento do seu real funcionamento:

- $\quad$ Browser (navegador): é o programa utilizado para visualizar as páginas da internet. Por exemplo, o internet explorer e o googlechrome;

- $\quad$ Provedor de serviço de internet: é a empresa responsável por fornecer a internet para o usuário;

- Domínio: nome que identifica um computador, departamento ou organização;

- Endereço IP (Internet Protocol): é o protocolo da Internet usado para identificar, localizar e estabelecer conexão entre computadores ligados à Internet;

- DNS (Domain Name System): é um sistema hierárquico de base de dados distribuídas, que converte um nome de domínio (nome que identifica o computador) em um endereço IP (protocolo de internet) do computador/servidor de Internet de um provedor de acesso e hospedagem de websites;

- $\quad$ FTP (File TransferProtocol): protocolo de transferência de arquivos pela Internet. É o método padrão de enviar arquivos entre computadores pela rede.

Outras duas leis relacionadas a internet foram sancionadas antes do Marco Civil.

A afamada Lei de Azeredo foi uma proposta que antecedeu o Marco Civil da Internet (Lei no 12.965/2014) para regular determinadas ocorrências na rede, possuindo uma desaprovação da sociedade que temia por sua liberdade de expressão e privacidade na internet.

Inicialmente, o projeto de lei pretendia incluir no Código Penal algumas diretrizes, como por exemplo, o estelionato eletrônico e regras mais severas para o armazenamento de dados de usuários, com o intuito de identificar suspeitos. Porém, o que foi aprovado foi somente um alvitre (proposta) para a investigação dos crimes cibernéticos, e uma expansão para a ação dos juízes nestes casos.

A lei Carolina Dieckmann, no 12.737/2012, aderiu informalmente a este nome em decorrência da divulgação não autorizada na rede (internet) de fotos nuas da atriz brasileira Carolina Dieckmann. Incorporou ao Código Penal quatro artigos que criminalizam a invasão de dispositivos informáticos: falsidade ideológica no caso do cartão (crédito ou débito) e qualquer interrupção ou perturbação de serviços eletrônicos, além de algumas causas de aumento de pena (Artigos 266, 298, 154-A e 154-B do Código Penal).

Apesar de estarmos no século XXI, poucos países estabeleceram regras para o uso da internet.

Na Espanha, a lei que "regula a internet" é chamada de Sinde-Wert, e foi promulgada no ano de 2010. Possui um controle maior das informações que circulam na rede, podendo retirar este conteúdo da internet caso viole a propriedade intelectual de terceiros, garantindo a sustentabilidade do setor econômico e o seu desenvolvimento, além de poder interromper o acesso à internet dos infratores. O Estado alega que a ausência de um controle da internet 
dificulta a investigação de crimes cibernéticos, o que causou um manifesto na população espanhola, denominado de "Manifesto em Defesa dos Direitos Fundamentais na Internet", acarretando questionamentos sobre a lei. (SEGURADO, LIMA, AMENI, 2014).

A França, possui uma das mais rígidas legislações da internet no mundo, conhecida como Lei da Criação e Internet, ou Hadopi, que possui um dispositivo de controle, sendo uma autoridade pública e independente de monitoramento do fluxo de conteúdos da rede e incentivo ao download legal. É um país que inovou ao desenvolver políticas em prol da propriedade intelectual. Seu sistema funciona de uma forma prática e funcional, onde constatada a infração o usuário recebe uma notificação por e-mail, caso volte a infringir, é solicitado ao provedor de internet que repasse os dados dele para serem tomadas as possíveis medidas cabíveis, como interrupção do seu serviço de internet, entre outros. (SEGURADO, LIMA, AMENI, 2014).

Nos EUA, as leis que abordam a internet são fragmentadas. Existindo, por exemplo, a $A$ Children's Online Privacy Protection Act (COPPA - lei da proteção da privacidade das crianças online) que protege as informações pessoais das crianças com menos de 13 anos de idade; e a Online Copyright Infringement Liability LimitationAct(OCILLA - lei de limitação de responsabilidade de infração de direitos autorais on-line), entre outras. O fato é que nos EUA existem conflitos sobre o controle da rede, onde a privacidade e a liberdade de informação entram em conflito com o governo. (SEGURADO, LIMA, AMENI, 2014).

O Chile foi o primeiro país a regulamentar a internet baseando-se no princípio da neutralidade da rede, que não permite a interferência em qualquer conteúdo publicado na internet (tráfego de informações), ou seja, a retirada de determinado conteúdo que circula na rede pelas provedoras que fornecem o acesso a internet não é permitido. (SEGURADO, LIMA, AMENI, 2014).

A Lei de neutralidade da rede do Chile foi elaborada de uma forma democrática, sendo aprovada no ano de 2010, contendo muitas outras particularidades importantes, como por exemplo, a exigência das empresas que fornecem o serviço de internet publicarem em seus sites, todas as características dos serviços fornecidos. (SEGURADO, LIMA, AMENI, 2014)

Devido às dúvidas expostas pela sociedade sobre a Lei Azeredo, em seu projeto inicial, e às espionagens que o governo brasileiro sofreu do governo norte americano (Edward Snowden, exanalista da Agência de Segurança Nacional - NSA dos EUA), o Marco Civil da Internet (PL 2126/2011) passou a existir, sendo elaborado de uma forma colaborativa, envolvendo a Secretaria de Assuntos Legislativos do Ministério da Justiça, o Centro de Tecnologia e Sociedade da Escola de Direito da Fundação Getúlio Vargas no Rio de Janeiro e a sociedade brasileira, onde internautas sugeriram modificações no projeto original da referida lei, além de debates públicos, que permitiram a usuários enviarem sugestões através de e-mails e comentários. (SEGURADO, LIMA, AMENI, 2014).

O Marco Civil da Internet foi sancionado como Lei 12.965/2014, possuindo 32 artigos. Apresentado na Conferência Multissetorial Global sobre o Futuro da Governança da Internet (NET Mundial), realizada em São Paulo, nos dias 23 e 24 de abril de 2014. Consistindo em um considerável progresso para o ordenamento jurídico brasileiro, tornando-se essencial para pacificar conflitos que decorrem do uso da internet no Brasil. Influenciando de uma forma ampla a área do Direito Digital, antes regrada pelo Código Civil, Código de Defesa do Consumidor e outras legislações, devido a ausência de uma lei específica sobre o tema, amparando o Poder Judiciário sobre questões que envolvam a matéria. Comparando-se, desta forma, a uma constituição (conjunto de normas, regras e leis) da internet, dispondo sobre o assunto no Brasil, organizando-o e regulando-o.

Uma das importantes características do Marco Civil da Internet, é que ele não está essencialmente voltado para o Código Penal, criminalizando determinadas condutas. Seu desígnio está para a proteção dos usuários, o que envolve sua liberdade de expressão entre outros direitos 
reservados a eles. Possui a finalidade de acabar com a censura e a remoção de textos desde que não viole o direito de outrem. Abordando a ideia de que a internet não pertence somente a um determinado país, mas sim, a todos em uma escala mundial. Sendo uma ferramenta utilizada vastamente em nosso mundo globalizado (integração social, cultural, política e econômica entre os países) para diversas atividades, sejam estas lícitas ou ilícitas. Exercendo uma finalidade social, transformando a coletividade e expondo opiniões, onde os direitos humanos (direitos básicos) devem ser respeitados, e todos podem e devem exercer sua cidadania. Não sendo somente uma forma de entretenimento, mas também de trabalho, abrangendo desta forma o comércio, onde deve estar presente os princípios da livre-iniciativa e da livre-concorrência.

Possui o objetivo do direito ao acesso da internet para todos, algo extremamente difícil em um país onde ainda existem regiões que não possuem, por exemplo, saneamento básico, desprovidos de uma infraestrutura adequada para suprir as necessidades básicas dos cidadãos.

Um dos pontos que tem gerado muitas discussões é sobre o armazenamento do registro dos usuários, ato que sempre foi de praxe entre as empresas que prestam o serviço na rede, uma forma de garantir sua defesa ou até mesmo disponibilizar ao usuário a consulta de seus registros por motivos particulares. Com as novas medidas, essa base de dados pode ser acessada através de uma ordem judicial, sem o consentimento da empresa e do cliente, como já ocorre com os registros telefônicos. Por um lado, isso é ótimo para o Sistema Judiciário obter provas dos fatos ilícitos praticados, entretanto, muitos alegam ser prejudicial à privacidade dos usuários. É uma regra que se estende também aos fornecedores da internet, não podendo revelar dados pessoais dos usuários para outras empresas, o que ocorria com frequência.

É importante ressaltar o direito de exclusão presente no Marco Civil, onde após efetuar o cancelamento dos serviços de um provedor, este fica obrigado a apagar os dados pessoais dos usuários. Conforme menciona Damásio de Jesus e José Antonio Milagre (2014, pag. 36):

Recentemente, quando deixávamos um serviço na internet, não sabíamos se efetivamente os provedores apagavam nossos dados. Em muitos casos era cediço, embora excluíssemos nossas contas, nossos dados permaneciam disponíveis ou armazenados. Com o Marco Civil, o usuário poderá requerer a exclusão definitiva de seus dados pessoais fornecidos a uma aplicação de internet, e o provedor deverá atender, ressalvados, logicamente, os dados que deva guardar por disposição legal.

A neutralidade da rede reside no aspecto dos provedores não interferirem no tráfego da rede (trafficshaping), na velocidade e no conteúdo que o usuário acessa. Em outras palavras, em determinados horários ou quando acessamos determinados sites ou funções, a internet fica mais lenta. Isto ocorre quando muitas pessoas acessam a rede a partir de um mesmo provedor (empresa que fornece a internet), alguns a deixando mais pesada, baixando vídeos e músicas (operações que sobrecarregam a rede). Para garantir que todos os usuários tenham a mesma velocidade de acesso (não significa ser mais rápido), o provedor realiza o trafficshaping, estabelecendo certas prioridades no trafego da rede, que na maioria das vezes entra em conflito com as prioridades dos próprios clientes. Conforme salienta Damasio de Jesus e Jose Antonio Milagre (2014, p. 43):

Na prática, todos os pacotes de dados devem ter o mesmo tratamento no que tange à velocidade do tráfego, não podendo o provedor reduzir a velocidade de acordo com o conteúdo acessado, sua origem e destino, o serviço ou à aplicação utilizada, ou mesmo de acordo com o "ter- minal que acessa" determinado serviço. 
Aos provedores fica proibido o trafficshaping, ou seja, o provedor não poderá priorizar ou mitigar o tráfego de acordo com o que é acessado. Essa prática ainda é comum no Brasil. Já quanto aos conteúdos ofensivos postados na internet, só podem ser retirados pelo provedor com decisão judicial, conforme dispõe o artigo 19 do Marco Civil. Como exceção, o artigo 21 discorre sobre as imagens pornográficas que violam a intimidade de terceiros, podendo o ofendido, solicitar a retirada de suas próprias imagens publicadas ao provedor, sem autorização judicial.

O Marco Civil da Internet locupletou o ordenamento jurídico brasileiro, oferecendo uma segurança legal para usuários e fornecedores da internet, possibilitando aos operadores do direito um alicerce quanto ao contexto do tema, antes superficial.

\section{CONSIDERAÇÕES FINAIS}

Com base no estudo desenvolvido neste trabalho, é possível afirmar que apesar de toda essa segurança jurídica que o Marco Civil da internet parece nos proporcionar, o Brasil ainda encontra dificuldades em relação à aplicação das leis por parte do judiciário. Além da ocorrência de determinados casos em nosso país, que deixam a sociedade em dúvida com relação aos seus direitos na internet.

Foram vários os episódios em que a justiça brasileira tentou bloquear o whatsapp (aplicativo de serviço de mensagens pela internet) em todo o país, em decorrência de desentendimentos entre o poder judiciário e os donos da empresa, que se recusaram a entregar informações para uma investigação. É importante ressaltar que não devemos extrair a razão do poder judiciário, o qual apenas tentou encontrar uma maneira de punir aqueles que não colaboraram para a realização das investigações. Porém, esta forma de coima prejudicou vários cidadãos que não tiveram relação com o ocorrido. É compreensível que o Estado detenha o "jus puniend" (direito de punir), contudo, isto não lhe autoriza a prejudicar vários outros indivíduos, tornando-se necessário uma solução acessível para ambos os lados, pois é uma situação que ocorrerá continuamente no Brasil.

\section{REFERÊNCIAS}

JESUS, Damásio de; MILAGRE, José Antonio. Marco Civil da Internet: Comentário à Lei 12.965/14. 1. ed. São Paulo: Saraiva, 2014.

PAGANOTTI, Ivan: Pressão Virtual e Regulamentação Digital Brasileira. Revista Eptic Online Vol.16 n.2 p.143-160 mai-ago 2014. Recebido em 03/03/2014. Aprovado em 30/04/2014.

SEGURADO, Rosemary; LIMA, Carolina Silva Mandú de; AMENI, Cauê S. Regulamentação da internet: perspectiva comparada entre Brasil, Chile, Espanha, EUA e França. História, Ciências, Saúde - Manguinhos, Rio de Janeiro. Disponível em: http://www.scielo.br/hcsm.

ABREU, Karen Cristina Kraemer: História e usos da Internet. Biblioteca online de ciências da comunicação BOCC, 2009. Disponível em: http://www.bocc.ubi.pt/.

Lei de Azeredo sancionada pela Presidência da República. Disponível em: <http://www.planalto.gov.br/ccivil_03/_Ato2011-2014/2012/Lei/L12735.htm>. Acesso em: 20 de março de 2016).

Lei Carolina Dieckmann sancionada pela Presidência da República. Disponível em:<http://www.planalto.gov.br/ccivil_03/_ato2011-2014/2012/lei//12737.htm>. Acesso em: 20 de março de 2016. 
Marco Civil da Internet - tramitação e conteúdo do projeto. Disponível em: $<$ http://www.camara.gov.br/proposicoesWeb/fichadetramitacao?idProposicao $=517255>$. Acesso em 20 de março de 2016.

Modificações sugeridas para 0 projeto original por internautas. Disponível em:< http://culturadigital.br/marcocivil/>. Acesso em: 9 de julho de 2016.

Síntese de eventos os quais o whatsapp foi bloqueado no Brasil. Disponível em: <http://g1.globo.com/tecnologia/noticia/2016/07/whatsapp-bloqueado-relembre-todos-os-casosde-suspensao-do-app.html>. Acesso em 14 de agosto de 2016. 